\title{
O MESTRADO PROFISSIONAL EM EDUCAÇÃO PROFISSIONAL E SUA CONTRIBUICCÃO PARA A AMPLIAÇÃO DO RECONHECIMENTO DOS INDÍGENAS NO ESTADO DE ALAGOAS
}

\author{
Adriana Cirqueira Freire*; Beatriz Medeiros de Melo \\ E-mail*: adriana.cirqueira@ifal.edu.br \\ *Instituto Federal de Alagoas \\ DOI: $10.15628 /$ rbept.2020.9870
}

Artigo submetido em: abr./2020 e aceito em: maio/2020

\begin{abstract}
RESUMO
Este artigo aborda a importância da discussão da temática indígena nas salas de aula do Instituto Federal de Alagoas (IFAL) e a contribuição do Mestrado Profissional em Educação Profissional e Tecnológica (ProfEPT) para o tratamento de temáticas locais, muitas vezes negligenciadas. De cunho bibliográfico, documental e reflexivo, discute três pontos: (1) o ProfEPT e o produto educacional, (2) a educação integral e a obrigatoriedade da inclusão da temática "História e Cultura Afro-Brasileira e Indígena" no currículo oficial das escolas públicas e privadas e (3) a relevância do estudo da história e a cultura dos povos indígenas alagoanos nas salas de aula do IFAL. Nas considerações finais apontamos a possibilidade de que os produtos educacionais produzidos no âmbito do ProfEPT contribuam para o aperfeiçoamento da prática educativa e para a ampliação do reconhecimento do contexto local/regional pela comunidade escolar.
\end{abstract}

Palavras-Chave: Educação Profissional Integrada. População Indígena, Educação Integral. História. Cultura.

\section{THE PROFESSIONAL MASTERS IN PROFESSIONAL EDUCATION AND ITS CONTRIBUTION TO THE EXTENSION OF RECOGNITION ON INDIGENOUS PEOPLE IN THE STATE OF ALAGOAS}

\begin{abstract}
This article deals with the importance of discussing indigenous issues in the classrooms of the Federal Institute of Alagoas (IFAL) and how the Professional Master's Degree in Professional and Technological Education (ProfEPT) can contribute to the discussion of local themes, often neglected. Bibliographic, documentary and reflective, it discusses three points: (1) ProfEPT and its educational product, (2) comprehensive education and the mandatory inclusion of the theme "Afro-Brazilian and Indigenous History and Culture" in the official school's curriculum public and private and (3) the relevance of studying the history and culture of indigenous people from Alagoas in the Ifal classrooms. In the final considerations we point out the possibility that the educational products produced within the scope of ProfEPT contribute to the improvement of educational practice and to the enlargment of the conditions for the recognition of the local/regional context by the school community.
\end{abstract}


Keywords: Integratade Professional Education. Indigenous Population, Integral Education. History. Culture.

\section{INTRODUÇÃO}

O presente trabalho tem como objetivo discutir algumas possíveis contribuições do Mestrado Profissional em Educação Profissional e Tecnológica (ProfEPT) para a discussão de importantes problemas sociais, dando visibilidade a temáticas e grupos sociais silenciados, negligenciados, invisibilizados ou subalternos nas salas de aula dos Cursos Técnicos Integrados ao Ensino Médio do Instituto Federal de Alagoas (IFAL). Todavia, o debate é pertinente, também, ao Ensino Médio em geral.

Nesse sentido, este artigo lança luz sobre a possibilidade do tratamento da questão indígena local/regional nas salas de aula do Ensino Médio Integrado através de um produto educacional. Para subsidiar esse debate, levantamos uma discussão que passa (a) pela missão institucional dos Mestrados Profissionais e o papel dos produtos educacionais, (b) pelo conceito norteador das reflexões e práticas produzidas no âmbito do Mestrado Profissional em Educação Profissional e Tecnológica, "a educação politécnica, omnilateral", (c) pelo estabelecimento recente da exigência legal do tratamento da questão indígena nas escolas, e, por fim, (d) por alguns apontamentos importantes sobre a questão indígena em Alagoas, que colaboram para ressaltar a importância do tratamento do tema.

Tal reflexão se faz necessária, por um lado, em virtude da implementação da legislação que instituiu a obrigatoriedade da inclusão da temática "História e Cultura Afro-Brasileira e Indígena" no currículo oficial das escolas públicas e privadas, a Lei no 11.645/2008, que alterou a Lei de Diretrizes e Bases da Educação Nacional. Por outro lado, faz-se importante em função da evidente invisibilização das etnias indígenas, o que faz da proposição desse debate uma forma de contribuir para o aperfeiçoamento da prática educativa capaz de ampliar as condições de reconhecimento do contexto local pela comunidade escolar.

Assim, lançar luz sobre os percursos e sujeitos históricos "esquecidos" pelos livros didáticos pode colaborar na compreensão da gênese de alguns preconceitos reforçados cotidianamente pelos silenciamentos e estigmas. Compreendemos que propor, nas salas de aula do ensino profissional e tecnológico, o debate sobre a existência e a resistência dos povos indígenas alagoanos é uma importante contribuição do ProfEPT, que pode fortalecer os vínculos entre Pesquisa, Ensino e Extensão. 


\section{MESTRADO PROFISSIONAL EM EDUCAÇÃO PROFISSIONAL E TECNOLÓGICA E OS PRODUTOS EDUCACIONAIS}

A Educação Profissional e Tecnológica (EPT) oferecida pelos Institutos Federais (IFs) representa uma importante oportunidade de acesso das classes populares a um ensino geral de qualidade aliado à educação tecnológica e profissional. Sua excelência é produto de uma série de decisões e articulações institucionais, dentre as quais destacamos: uma estrutura verticalizada, que alcança da Educação Básica à Educação Superior; uma base alicerçada na indissociabilidade entre Ensino, Pesquisa e Extensão; qualificação de docentes; estrutura física e parcerias com universidades e setores produtivos. Em 2017, a fim de fortalecer essa excelência, foi criado o Programa de Pósgraduação em Educação Profissional e Tecnológica em Rede Nacional (ProfEPT). De acordo com o Artigo $2^{\circ}$ do Regulamento do Programa, o ProfEPT

(...) tem como objetivo proporcionar formação em educação profissional e tecnológica, visando tanto a produção de conhecimentos como o desenvolvimento de produtos, por meio da realização de pesquisas que integrem os saberes inerentes ao mundo do trabalho e ao conhecimento sistematizado. (BRASIL, 2018, p. 2).

O programa apresenta duas linhas de pesquisa: Práticas Educativas em Educação Profissional e Tecnológica (EPT) e Organização e Memórias de Espaços Pedagógicos na Educação Profissional e Tecnológica (EPT). A primeira linha de pesquisa se divide em três macroprojetos: 1 - Propostas metodológicas e recursos didáticos em espaços formais e não formais de ensino na EPT; 2 - Inclusão e diversidade em espaços formais e não formais de ensino na EPT; 3 - Práticas Educativas no Currículo Integrado. A segunda linha de pesquisa se divide em outros três macroprojetos: 4 - História e memórias no contexto da EPT; 5 - Organização do currículo integrado na EPT; 6 - Organização de espaços pedagógicos da EPT.

O ProfEPT visa qualificar técnicos e docentes para a gestão e para as práticas educativas em EPT, ampliando a dinâmica entre Pesquisa, Ensino e Extensão, e, ao mesmo tempo, abrindo espaço para estreitar diálogos com a sociedade. O programa está calcado na estreita articulação entre conhecimento teórico e aplicação prática. Como os demais Mestrados Profissionais instituídos pela CAPES (Portaria 389 de junho de 2017), há a exigência de um trabalho final de aplicação prática chamado de produto educacional, que pode ser apresentado em diversos formatos e deve responder a problemas reais diagnosticados através de diferentes mecanismos de pesquisa-ação.

Enquanto uma metodologia de caráter participativo e democrático, a pesquisa-ação é uma forma de investigação que visa contribuir para uma 
mudança social, sendo definida por Tripp (2005, p. 443) como "toda tentativa continuada, sistemática e empiricamente fundamentada de aprimorar a prática" e tendo sua orientação, segundo Thiollent (2007, p.16), na perspectiva da resolução de problemas em um contexto investigativo onde os envolvidos interagem e atuam de forma colaborativa na resolução de um problema coletivo.

Assim, para a obtenção do título de mestre no ProfEPT, além da produção de uma dissertação de mestrado como trabalho final do curso, é exigida a elaboração de um produto educacional que deve resultar de um trabalho de pesquisa na área do Ensino, vinculado a problemas reais, podendo ser apresentado em diversos formatos e abordando diferentes temáticas, quer sejam vinculadas diretamente à educação profissional e tecnológica, quer seja contribuindo para a concretização de uma educação omnilateral.

\section{EDUCAÇÃO INTEGRAL}

As bases conceituais para a EPT buscam a rearticulação entre trabalho e educação, considerando o trabalho como princípio educativo. Nessa direção, atua na construção de uma formação humana integral ou omnilateral, na perspectiva de emancipação dos sujeitos, da produção de indivíduos críticos e ativos. O capitalismo é inevitavelmente produtor e reprodutor de desigualdades e isso se estende às suas instâncias legitimadoras, dentre elas a própria escola. Todavia, ao adentrar este debate, Gramsci (1988) idealizou uma escola com menor influência do estado e maior atuação da sociedade civil, uma escola capaz de superar a dicotomia que marca os sistemas de ensino, fragmentados entre escolas para as classes populares e escolas para as classes dominantes, uma escola dotada de:

uma cultura geral, humanista, formativa, que equilibre equanimemente o desenvolvimento da capacidade de trabalhar manualmente (tecnicamente, industrialmente) e o desenvolvimento das capacidades de trabalho intelectual. (GRAMSCI, 1988, p. 118).

Uma educação capaz de produzir consciência a respeito da realidade injusta e desigual que sustenta as sociedades capitalistas poderia colaborar para sua superação e, a partir daí, da completa emancipação humana. Nesse sentido, a escola pode produzir condições para uma desalienação processual e para a construção de um cenário de contra-hegemonia, tal como defendia Gramsci (1988).

No caminho de tais reflexões, Lombardi (2002) se propôs a buscar respostas acerca da possibilidade de uma pedagogia marxista como parte de um projeto revolucionário de sociedade. Analisou os escritos de Suchodolski, Manicora e Dangevile e sistematizou uma visão da contribuição de Marx e Engels para a educação, destacando três aspectos 
1. Crítica à educação, ao ensino e à qualificação profissional burguesa. Analogamente à crítica da economia política, Marx e Engels também dirigiram ao ensino burguês uma aguda e profunda crítica desnudando a relação entre a educação e as condições de vida das classes fundamentais da sociedade burguesa; 2 . Relação do proletariado com a ciência, a cultura e a educação. O tratamento de Marx e Engels dado à problemática da relação do proletariado com a cultura e a ciência explicitava como entendiam a ciência a serviço do capital, o processo de alienação resultante do processo de trabalho industrial e o aparelhamento burguês da escola, bem como a importância da educação para a formação da consciência; 3 . Educação comunista e formação integral do homem - a educação como articuladora do fazer e do pensar - a superação da monotecnia pela politecnia. (LOMBARDI, 2002, p.36).

Essa concepção educacional, então, se sustentava sobre duras críticas à sociedade burguesa e, a partir daí, vislumbrava sua superação enquanto caminho imprescindível para o alcance da plena liberdade. Para Marx e Engels, portanto, a educação deveria estar a serviço da libertação e da formação integral de toda a humanidade.

Em Trabalho e Educação: fundamentos ontológicos e históricos, Demerval Saviani (2007) assenta as bases da noção de trabalho como princípio educativo. O autor define o trabalho como um processo histórico onde o homem aprende a ser homem, aprende a produzir sua existência, sendo essa formação um processo educativo. "A origem da educação coincide, então, com a origem do homem" (SAVIANI, 2007, p.154). Nas sociedades primitivas, o ato de conhecer e trabalhar ocorria simultaneamente, enquanto se trabalhava, se conhecia e eram construídos significados e sentidos ao ato praticado. Com as mudanças na organização social e no modo de produção, a divisão entre o pensar e o fazer foi se aprofundando e, com o advento da industrialização, o processo se acelerou de forma a cindir o trabalho em manual e intelectual. Essa ruptura também significou uma cisão no processo educativo, que passa a ser diferenciado entre as diferentes classes sociais, provocando "a separação entre instrução e trabalho produtivo, forçando a escola a ligar-se, de alguma maneira, ao mundo da produção" (ibidem, p. 159).

Vemos, assim, que as especificidades do ensino acompanham a dinâmica das relações sociais de produção nas diferentes épocas. Os níveis de ensino fundamental, médio e superior de hoje também seguem essa lógica em diferentes graus. Todavia, apesar dos imperativos do mercado, ao tratar do Ensino Médio, Saviani (2007, p. 164) apresenta possibilidades de uma formação pautada na práxis, com mais autonomia e criticidade, a partir dos conceitos marxistas de politecnia e omnilateralidade, que buscam superar a cisão produzida pelo trabalho estranhado, e vislumbram o desenvolvimento da capacidade de compreensão dos fenômenos e processos em sua integralidade e complexidade.

Na perspectiva politécnica da educação profissional integrada ao ensino médio, "o eixo central é a articulação entre a construção do conhecimento (ciência e tecnologia), cultura e trabalho como princípio educativo, manifestação de vida, direito e dever" (FRIGOTTO, CIAVATTA, RAMOS, 2005, p. 15). Isso significa dizer que essa concepção se contrapõe ao tipo de 
formação que submete os jovens à lógica do trabalho alienado, fragmentado e focado no emprego e na sujeição. Nela, a noção de formação omnilateral compreende o desenvolvimento integral do indivíduo em todas as potencialidades e em todos os sentidos, envolvendo o trabalho, a ciência e a cultura.

O Projeto Político Pedagógico Institucional (PPPI) do IFAL incorpora o princípio da politecnia. Ao tratar da organização didático-pedagógica institucional, explicita

o IFAL perseguirá sua missão com base no princípio de igualdade de condições para o acesso (tendo como premissa a inclusão social) e permanência com sucesso na escola - observando a liberdade do aluno em aprender e do professor em ensinar, tendo como um dos objetivos a divulgação da cultura, do pensamento, o pluralismo de ideias de concepções pedagógicas, valorizando a experiência extracurricular vinculada à educação ao trabalho e às práticas sociais - sem desconsiderar os princípios da competência, da laborabilidade, da flexibilidade, da interdisciplinaridade e da contextualização, além de delinear os perfis de formação que respondam às exigências da contemporaneidade. (BRASIL/IFAL, $p$. 36).

Todavia, o diagnóstico da rede dos Institutos Federais apresentado no texto citado, realizado por Dante Moura, indica que não houve uma preparação adequada dos professores para a correta implementação da proposta de formação integrada. Ele afirma que a resistência perceptível nos professores se deu por várias questões, entre elas a forma impositiva com que a proposta foi implementada, os padrões pedagógicos conservadores, o desconhecimento conceitual e a dificuldade em envolver os professores temporários, entre outras. (FRIGOTTO, CIAVATTA, RAMOS, 2005, p.16).

Consideramos que, apesar dos limites na implementação da proposta, é imprescindível continuar caminhando em sua direção, a fim de contribuir para a promoção de uma formação integral e de uma sociedade mais justa, menos desigual. Por isso, o produto educacional que nos propomos a construir colabora nessa direção, construindo mecanismos para levar a temática indígena, uma temática recorrentemente negligenciada, para o contexto da formação geral dos cursos técnicos integrados ao Ensino Médio, em linguagem acessível e dentro dos parâmetros da proposta educacional da politecnia, subsidiando um debate contemporâneo e necessário, sobre o qual passaremos agora a tratar.

\section{A QUESTÃO INDÍGENA NOS CURRÍCULOS ESCOLARES}

Consideramos a princípio que o Art. 26 da Lei no 9.394, de 20 de dezembro de 1996 (BRASIL, 1996) da Lei de Diretrizes e Bases da Educação 
Nacional (LDB) preceitua que os currículos da educação básica (ensino infantil, fundamental e médio) devem ter, em cada estabelecimento escolar, independente do sistema de ensino, "uma parte diversificada, exigida pelas características regionais e locais da sociedade, da cultura, da economia e dos educandos" (BRASIL, 1996, n.p. ).

Por outro lado, a Lei 10.639, aprovada em janeiro de 2003, tornou obrigatório o ensino de História e Cultura Afro-Brasileira nos estabelecimentos de ensino públicos e privados do país, alterando o Art. 26 da LDB. Em março de 2008 uma nova lei altera a LDB, anteriormente modificada pela Lei 10.639/2003: a Lei o 11.645 de 10 de março de 2008 instituiu a obrigatoriedade da inclusão da temática História e Cultura Afro-Brasileira e Indígena no currículo oficial das redes de ensino, ampliando ainda mais o artigo 26 da LDB (BRASIL, 1996, n.p.)

\begin{abstract}
Art. 26-A. Nos estabelecimentos de ensino fundamental e de ensino médio, públicos e privados, torna-se obrigatório o estudo da história e cultura afro-brasileira e indígena.

$\S 1^{\circ} \mathrm{O}$ conteúdo programático a que se refere este artigo incluirá diversos aspectos da história e da cultura que caracterizam a formação da população brasileira, a partir desses dois grupos étnicos, tais como o estudo da história da Africa e dos africanos, a luta dos negros e dos povos indígenas no Brasil, a cultura negra e indígena brasileira e o negro e o índio na formação da sociedade nacional, resgatando as suas contribuições nas áreas social, econômica e política, pertinentes à história do Brasileiras;

$\S 2^{\circ}$ Os conteúdos referentes à história e cultura afro-brasileira e dos povos indígenas brasileiros serão ministrados no âmbito de todo o currículo escolar, em especial nas áreas de educação artística e de literatura e história brasileiras. (Redação dada pela Lei no 11.645, de 2008).
\end{abstract}

Em consequência da alteração da Lei o 9.394 pela Lei oํ 11.645/08, exigindo a inclusão da história e da cultura indígena nos currículos da Educação Básica, ampliou-se o estudo da diversidade cultural na formação do povo brasileiro. Todavia, apesar da ampliação desse esforço de investigação, há muitas dificuldades em tratar a temática em sala de aula de forma concreta e contextualizada, visto que a maioria dos livros didáticos expressam uma visão eurocêntrica e nacionalista da história.

A proposta de implementação de um ensino multicultural de forma interdisciplinar, principalmente nas disciplinas de Artes, História e Língua Portuguesa, tratando as relações étnico-raciais no cotidiano das instituições em espaços formais e não-formais, não é tarefa simples. Sobretudo considerando que existe pouca formação e/ou materiais adequados disponíveis aos educadores. Assim, um produto educacional para auxiliar no tratamento dessa temática pode oferecer subsídios capazes de auxiliar na abordagem de diferentes temas. 
O silenciamento nas questões culturais e históricas indígenas é produto do não reconhecimento da importância desses povos na formação do povo brasileiro, o que resulta, muitas vezes, em posturas rígidas e verticalizadas, com hierarquização e discriminação entre as diferentes culturas formadoras da nossa sociedade. Compreendemos, de outra forma, que o estudo da formação da identidade do povo brasileiro passa pelo conhecimento da história e cultura das populações indígenas e é tema que pode ser tratado interdisciplinarmente nas disciplinas sugeridas na legislação.

Os PCNs (Parâmetros Curriculares Nacionais) também pontuam a importância dessa abordagem. O capítulo "A organização curricular da Base Nacional Comum do Ensino Médio" explicita que a relação do presente com o passado deve apresentar a compreensão do tempo como algo dinâmico e capaz de possibilitar a ampliação dos saberes sem retirá-los da sua historicidade. Desta forma, a interação entre as diversas etnias formadoras do povo brasileiro deve ser apresentada nos currículos de forma equânime, sem dissimulações ou ocultamentos. Os PCNs indicam, ainda, a necessidade de ampliar a compreensão sobre o lugar que o indígena precisa ocupar na sala de aula para que os estudantes sejam capazes, entre outros aprendizados, de entenderem as múltiplas memórias e contribuições e, principalmente, a se posicionarem no lugar do outro.

Ao discorrer sobre a contribuição indígena na formação de Alagoas, Silva (2011) aponta a necessidade de relacionar a história indígena com a sociedade, os meios de produção e o poder local no séc. XIX. Para ele, colonizadores e indígenas possuem histórias diferentes, que se construíram sobre perspectivas diversas, e a história oficial não contempla a vida, o trabalho e os enfrentamentos desta população. Essa ausência sistemática, esse silenciamento sobre os indígenas nos currículos escolares e, consequentemente, nos livros didáticos, é vista por Arroyo (2011) como intencionalidade política e não como um esquecimento.

Sendo o livro didático um dos principais instrumentos da prática pedagógica e, muitas vezes, a mais importante fonte de leitura dos estudantes das escolas públicas, é importante que seja bem construído e possa oferecer as ferramentas que o professor precisa para organizar uma aula qualificada e atrativa para o estudante, com diferentes tipos linguagens e conteúdos (texto, imagens, sugestões de leituras suplementares, links para a internet). O material didático deve ser redigido de forma a comunicar de forma clara, sintética e problematizadora, a fim de garantir o reconhecimento das principais problemáticas que giram em torno dos temas propostos.

Para que a legislação seja cumprida e essa discussão travada de maneira adequada, ela precisa ser realizada no contexto da interdisciplinaridade, através da mediação entre as disciplinas e em constante e diversificado diálogo. Nesse sentido, as práticas educativas ensejadas no âmbito do ProfEPT têm sido pensadas de forma dialógica e se propõe a auxiliar na formação de estudantes críticos e reflexivos, capazes de compreender a dinâmica social e as especificidades da realidade brasileira no que tange às diferenças e identidades, muitas vezes não percebidas no cotidiano da comunidade escolar. 
A proposição de um produto educacional que subsidie a proposição de discussões acerca da contribuição indígena para a construção de uma identidade nacional colabora para o aperfeiçoamento e a ampliação do conteúdo da formação integral dos estudantes do Ensino Médio Integrado do Instituto Federal de Alagoas. Desse modo, no tópico seguinte apresentamos algumas informações e debates significativos que propomos levar à sala de aula.

\subsection{ALGUNS APONTAMENTOS SOBRE OS POVOS INDÍGENAS DE ALAGOAS}

De acordo com o Censo Demográfico realizado pelo Instituto Brasileiro de Geografia e Estatística (IBGE) em 2010, a população indígena brasileira é de 896.917 pessoas ( $0,4 \%$ da população). Em Alagoas, 14.509 pessoas se autodeclararam indígenas ( $0,5 \%$ do Estado). Hoje esse número é de aproximadamente 20 mil. A inclusão da discussão aqui proposta no currículo do Ensino Médio Integrado do IFAL através da construção de um produto educacional poderia fomentar uma nova forma de se conceber a contribuição das etnias indígenas alagoanas, que supere as concepções eurocêntricas e afaste do imaginário dos estudantes a ideia de assimilação cultural, estimulando uma visão anti-hegemônica e mais inclinada ao convívio das diferenças.

Ao tratar da temática, defendemos a necessidade de uma compreensão histórica, contextualizada, a respeito de quem foram e quem são hoje estes sujeitos indígenas. Desse modo, vamos a alguns elementos importantes a recuperar.

Almeida (2010) esclarece que, durante a colonização, os indígenas eram identificados pela perspectiva europeia como seres irracionais, tal qual a natureza e os animais, e que, por isso, precisavam ser domesticados, levados à situação de civilidade. Eles não fazem parte da historiografia tradicional de maneira consistente. Exemplo disso são o genocídio e a desterritorialização, ocorridos entre os séculos XVI e XIX, das nações indígenas brasileiras, bem como a subsequente transformação de suas terras ancestrais em terras devolutas pela Constituição Republicana de 1891.

Nessa mesma direção, Silva (2011), em seu estudo sobre os índios das matas alagoanas através de documentos oficiais do século XIX e sobre a força de trabalho indígena na perspectiva dos poderosos, demonstra como foi a construção da imagem do indígena preguiçoso, incapaz e ladrão - que se opunha ao ideal civilizatório da época, baseado no trabalho, na produção e na propriedade 
própria terra; [...] É uma imagem que reflete a ausência de civilização, que é traduzida como ausência de trabalho, de produtividade e de propriedade, e que culmina com a ausência do próprio índio como membro da sociedade. (SILVA, 2011, p.3).

Para compreender como vivia a população indígena, precisamos considerar, dentre outros fatores, o impacto do modo de produção colonial sobre o modo de vida dos povos originários. Havia grupos que resistiam aos aldeamentos e ainda viviam nas matas, ocupando a floresta e dela tirando seu sustento. A autoridade da época precisava colocá-los sob seu domínio para que sua presença não fosse capaz de ameaçar a ordem vigente.

A conquista da terra e o controle dos indígenas foi fundamental para a consolidação da sociedade alagoana, que se deu com a conquista da terra e o controle dos índios, inclusive do seu trabalho. A conquista das matas era condição fundamental para dar continuidade a esse movimento. Foi justamente o que aconteceu no século XIX, com a destruição dos Cabanos do Jacuípe e com fim dos últimos aldeamentos nas matas alagoanas, consolidando a política de mando local sobre o trabalho e a propriedade indígenas. (SILVA, 2011, p.6).

A terra é elemento central de reprodução social indígena. Silva (2007, p. 106) afirma que, historicamente, o objetivo do sistema foi transformar "a mão de obra indígena em reserva de mercado." Sem a terra, o índio perde o seu principal elemento de sustentação e, quando não a tem para sobreviver, se transforma em reserva de mão de obra, se adequando aos interesses do capital. Assim, sem terra própria onde trabalhar e executar seus rituais e tradições, o indígena se vê empurrado para uma adequação ao sistema de produção vigente, adequação forçada sob argumento da integração à sociedade ocidental.

Consideramos necessário, ainda, refletir sobre etnogênese, debate que pode desmistificar a ideia romântica de 'pureza' étnica. Nesse sentido, Silva (2007) pontua o processo de etnogênese, a partir dos Pankararu e dos Geripankó. Explica que a formação desses povos "passa pelo processo dinâmico das relações entre os grupos constituintes da sua etnia, historicamente formado em um Nordeste de exploração e luta" (SILVA, 2007, p. 107), em um contexto onde a exploração à qual foram submetidos fez emergir novas etnias. A usurpação das terras dos Pankararu e seu êxodo deu origem aos Geripankó. Assim, com separações em alguns grupos e uniões de outros, vários povos indígenas foram se formando. As relações de parentesco com os Pankararu e as experiências comuns de resistência auxiliaram no aprofundamento das tradições e rituais, como depois aconteceu com os grupos ligados à mesma matriz, os Karuazu, Katokin e Koipanká, além dos próprios Geripankó. 
Também Amorim (2003, apud SILVA, 2007), ao destacar a importância e o apoio do tronco Pankararu para fortalecer o reconhecimento das comunidades indígenas ressurgidas, afirma que essas comunidades são "ramas" desse tronco que surgem como aldeias. Cada "rama de tronco" permite a formação de uma aldeia que pode ter seu próprio nome graças a esse reconhecimento dado pelo grupo ancestral, que oferece condições para essa legitimação e posteriormente, "para o reconhecimento oficial e sua posterior identificação, delimitação e demarcação de terras indígenas" (SILVA, 2007, p. 120).

Sobre a formação da identidade indígena, Silva (2008, p.108) salienta que o sentimento de pertença a uma sucessão de gerações fundamenta uma identidade ligada à uma história de resistência. Essa ideia está associada ao lugar, à tradição, à religião, à família, ao modo de vida ligado à terra como espaço de produção e de organização social. A terra, seus significados e usos, tem importância fundamental na vida do povo Geripankó, "seu modo de vida foi construído dentro de um modo de produção que influenciou de forma decisiva as suas estratégias de resistência e a formação de seu território".

Fortalecidos pelas lutas sociais apoiadas por instituições como as Universidades, a Igreja Católica e organizações não-governamentais e incorporadas, posteriormente, na Constituição Federal de 1988, diversas comunidades no Nordeste se reivindicaram como indígenas e passaram a se organizar e resistir. João Pacheco de Oliveira (1998) argumenta que o processo histórico ao qual foram submetidos os indígenas do Nordeste, os "índios misturados", desde a colonização, teve o objetivo de homogeneizar as etnias e misturá-las ao restante do povo, o que acarretou o ocultamento de suas manifestações culturais, a alteração de sua aparência física e a perda de seus idiomas e territórios.

O Artigo 231 da Constituição Federal (CF) de 1988 reconhece aos índios "os direitos originários sobre as terras que tradicionalmente ocupam". O texto constitucional indica que são consideradas terras indígenas:

[...] as terras ocupadas em caráter permanente, as utilizadas para suas atividades produtivas, as imprescindíveis à preservação dos recursos ambientais necessários a seu bem-estar e as necessárias à sua reprodução física e cultural. (BRASIL, 1988, n.p.).

Além da CF, com suas disposições garantidoras da proteção e promoção dos direitos dos povos indígenas, em 2002 o Brasil ratificou a Convenção no 169 da Organização Internacional do Trabalho (OIT) sobre Povos Indígenas e Tribais. Apesar disso muitas terras com essas características ainda não estão regularizadas. Não obstante, terra indígena e território indígena são noções distintas. Enquanto o primeiro diz respeito ao processo legal, o último está ligado à vivência e pertencimento.

No século XX, pequenos grupos indígenas no nordeste dados como extintos, ou tão miscigenados que já não seria possível distingui-los do restante Vol. 2 (2020) 
do povo, desaldeados, buscam recuperar sua identidade indígena e seus direitos historicamente usurpados, sendo a retomada de seus territórios o mais importante deles. Esses povos têm seu pertencimento étnico mais ligados às relações comunitárias, relacionadas ao modo de vida e tradição e na religiosidade, do que simplesmente à questão de hereditariedade.

Atualmente existem em Alagoas onze nações indígenas: os Xucurukariri (Palmeira dos Índios), Wassu Cocal (Joaquim Gomes), Kariri-xocó (Porto Real do Colégio), Aconã (Traipu), Tingui-botó (Feira Grande), Geripancó (Pariconha), Kalancó (Água Branca), Karapotó (São Sebastião), Karuazú (Pariconha), Katokin (Pariconha) e os Koiupanká (Inhapi). Existem processos de demarcação de terras em diversos estágios, mas nenhum concluído em sua totalidade. Mesmo o reconhecimento da tradicionalidade de alguns povos do sertão se arrasta há décadas sem que seja atestado oficialmente pelo Estado brasileiro, inviabilizando suas lutas pela (re)conquista de territórios.

\section{REFLEXÕES FINAIS}

A construção de um produto educacional capaz de levar para as salas de aula as discussões aqui levantadas poderá, por um lado, dar visibilidade a um grupo social historicamente marginalizado, e, por outro, dar a conhecer as especificidades dos povos indígenas alagoanos, suas peculiaridades e sua história de resistência. Lançando um olhar contextualizado e crítico, colaborando, dessa forma, para implementação da Lei $n^{0} 11.645$ no que toca à questão indígena, bem como para o cumprimento da LDB no que diz respeito ao reconhecimento dos contextos regionais nos currículos escolares.

Com a elaboração de produtos educacionais que abordem temáticas que possam ser tratadas de forma interdisciplinar, que levem à criticidade $e$ auxiliem na mudança de atitude diante das mais diversas situações sociais, o ProfEPT pode, de maneira organizada e metodologicamente adequada, ocupar um espaço que hoje depende de iniciativas isoladas.

Sabemos dos diversos limites que impedem que docentes das diferentes disciplinas produzam materiais didáticos tão específicos como o que propomos: a extensa jornada de trabalho; as muitas horas dedicadas à preparação de aulas, avaliações e reavaliações; o limitado tempo para qualificação profissional; a qualificação profissional especialista, limitada a um universo de investigação específico; dentre outras. Desse modo, munindo-nos de resultados de investigações científicas sobre os grupos indígenas alagoanos, esperamos levar aos estudantes, de maneira didática e contextualizada, um debate que promova reflexões sobre inclusão, diversidade e a prática da alteridade e, ao mesmo tempo, amplie o reconhecimento da realidade local/regional. Aos professores, esperamos ofertar oportunidades de melhor orientá-los nessa reflexão contemporânea, alinhada à perspectiva de cidadania e transformação social, proporcionando um espaço de formação integral ao estudante do Ensino Técnico Integrado. 


\section{REFERÊNCIAS}

ALMEIDA, Maria Regina Celestino de. Os índios na história do Brasil. Rio de Janeiro: Ed. FGV, 2010.

AMORIM, Siloe Soares. Indios ressurgidos: a construção da auto-imagem: os Tumbalala, os Kalanko, os Karuazu, os Catokinn e os Koiupanka. 2003. 301 p. Dissertação (mestrado) - Universidade Estadual de Campinas, Instituto de Artes, Campinas, SP. Disponível em:

http://www.repositorio.unicamp.br/handle/REPOSIP/284858. Acesso em: 03 ago. 2018.

ARROYO, Miguel. Currículo, território em disputa. Petrópolis: Vozes, 2011

BRASIL. Constituição da República Federativa do Brasil (1988). Promulgada em 05 de outubro de 1988. Disponível em:

www.planalto.gov.br/ccivil_03/constituicao/constituicaocompilado.htm. Acesso em: 21 set. 2019.

BRASIL. Instituto Brasileiro de Geografia e Estatística (IBGE). Os indígenas no Censo Demográfico 2010. Brasília. Disponível em https://ww2.ibge.gov.br/indigenas/indigena_censo2010.pdf. Acesso em: 21 set. 2019.

BRASIL. Lei no 9.394 de 20 de dezembro de 1996. Estabelece as diretrizes e bases da educação nacional). Brasília: dezembro de 1996. Disponível http://www.planalto.gov.br/ccivil_03/Leis/L9394.htm. Acesso em: 21 set. 2019.

BRASIL. Lei 10.639/2003, de 9 de janeiro de 2003. Altera a Lei no 9. 394, de 20 de dezembro de 1996. Diário Oficial da União, Poder Executivo, Brasília. Disponível em https://presrepublica.jusbrasil.com.br/legislacao/98883/lei10639-03. Acesso em: 21 set. 2019.

BRASIL. Ministério da Educação. Diretrizes Curriculares Nacionais para a Educação das Relações Étnico-Raciais e para o Ensino de História e Cultura Afro-brasileira e Africana. Brasília: outubro de 2005. Disponível em http://portal.mec.gov.br/cne/arquivos/pdf/res012004.pdf. Acesso em: 21 set. 2019.

BRASIL. Lei no $\mathbf{1 1 . 6 4 5}$ de $\mathbf{1 0}$ de março de 2008. Altera a Lei no 9.394, de 20 de dezembro de 1996, modificada pela Lei no 10.639, de 9 de janeiro de 2003, que estabelece as diretrizes e bases da educação nacional, para incluir no currículo oficial da rede de ensino a obrigatoriedade da temática "História e Cultura Afro-Brasileira e Indígena". Brasília: março de 2008. Disponível em http://www.planalto.gov.br/ccivil 03/ Ato2007-2010/2008/Lei/L11645.htm, Acesso em: 21 set. 2019.

BRASIL. Parâmetros Curriculares Nacionais. 2000. Disponível em http://portal.mec.gov.br/seb/arquivos/pdf/blegais.pdf. Acesso em: 21 set. 2019. 
BRASIL. Instituto Federal do Espírito Santo. O ProfEPT. Histórico. 2018. Disponível em https://profept.ifes.edu.br/sobreprofept, Acesso em: 21 set. 2019.

BRASIL. Instituto Federal do Espírito Santo. Mestrado Profissional em Educação Profissional e Tecnológica. Regulamento.. 2018. Disponível em https://profept.ifes.edu.br/images/stories/ProfEPT/Turma_2018/Regulamento/ Res_CS_22_2018_-_Regulamento.pdf. Acesso em: 22 set. 2019.

BRASIL. Instituto Federal de Alagoas. Projeto Político Pedagógico Institucional (PPPI). 2013. Disponível em https://www2.ifal.edu.br/ifal/reitoria/pdi/documentos-pdi-2019-2023/outrosdocumentos/pppi-2013.pdf. Acesso em: 22 set. 2019

BRASIL. Fundação CAPES. Mestrado Profissional: o que é? . Brasília. Disponível em http://capes.gov.br/avaliacao/sobre-a-avaliacao/mestradoprofissional-o-que-e. Acesso em: 21 set. 2019.

FRIGOTTO, G., CIAVATTA, M., RAMOS, M. O trabalho como princípio educativo no projeto de educação integral de trabalhadores. In: COSTA, H. e CONCEIÇÃO, M. (Org.). Educação integral, sistema de reconhecimento e certificação educacional e profissional. São Paulo: CUT, 2005, p.19-62.

GRAMSCI, Antonio. Os intelectuais e a organização da cultura. Rio de Janeiro: Civilização Brasileira, 1988.

LOMBARDI, José Claudinei. Educação, ensino e formação profissional em Marx e Engels. In: LOMBARDI, J. C., SAVIANI, D. (Org.). Marxismo e educação: debates contemporâneos. Campinas: Ed. Autores Associados Ltda, 2002. p. 27-64

OLIVEIRA, João Pacheco. Uma etnologia dos 'índios misturados' - situação colonial, territorialização e fluxos culturais. Mana - Estudos em Antropologia Social. Rio de Janeiro. v. 4, n. 1: 47-77 p. 1998.

SAVIANI, Dermeval. Trabalho e educação: fundamentos ontológicos e históricos. Rev. Bras. Educ., Rio de Janeiro, v. 12, n. 34, p. 152-165, Apr. 2007. Disponível em <http://www.scielo.br/scielo.php?

script=sci_arttext\&pid=S1413-24782007000100012\&lng=en\&nrm=iso $>$. Acesso em: 22 set. 2019.

SAVIANI, Dermeval. Sobre a concepção de politecnia. Rio de Janeiro:

Fiocruz, 1989. Disponível em https://docgo.net/detail-

doc.html?utm source=dermeval-saviani-sobre-a-concepcao-de-

politecnia\&utm campaign=download. Acesso em: 23 set. 2019.

SCHÄFER, Márcio Egídio. $O$ conceito de trabalho na filosofia de Hegel e alguns aspectos de sua recepção em Marx. 2012. 126 f. Dissertação (Mestrado em Filosofia) - Pontifícia Universidade Católica do Rio Grande do Sul, Porto Alegre, 2012. Disponível em

http://tede2.pucrs.br/tede2/handle/tede/2887. Acesso em: 23 set. 2019.

SILVA, Amaro Hélio Leite da. Proletarização Indígena no Alto Sertão de

Alagoas. In: Coleção Índios do Nordeste: temas e problemas, Vol. VIII, 2007 
SILVA, Amaro Hélio Leite da. Geripankó: a formação de um território indígena no alto sertão. In: ALMEIDA, Luiz Sávio de (Org.). Índios do Nordeste: etnia, política e história. Maceió: EDUFAL, 2008.

SILVA, Amaro Hélio Leite da. Trabalho Indígena na Formação das Alagoas (Século XIX): os índios das matas nas falas e relatórios oficiais. Anais do XXVI Simpósio Nacional de História - ANPUH. São Paulo, julho 2011. Disponível em http://www.snh2011.anpuh.org/resources/anais/14/1308187662 ARQUIVO T RABALHOINDIGENANAFORMACAODASALAGOAS.pdf. Acesso em: 22 set. 2019.

THIOLLENT, Michel. Metodologia da pesquisa-ação. 15 ed. São Paulo: Cortez, 2007.

TRIPP, David. Pesquisa-ação: uma introdução metodológica. Educação e Pesquisa, São Paulo, v. 31, n. 3, p. 443-466, set./dez. 2005. Disponível em: http://www.scielo.br/pdf/\%0D/ep/v31n3/a09v31n3.pdf. Acesso em: 23 set. 2019.

VIEIRA, Jorge L. Gonzaga. Povos do sertão de Alagoas: confinamento, diáspora e reterritorialização. Revista Fórum Identidades. Itabaiana: GEPIADDE, Ano 4, Volume 8. jul-dez de 2010. Disponível em https://seer.ufs.br/index.php/forumidentidades/article/viewFile/1777/1566. Acesso em: 23 set. 2019. 